\title{
Sistema Único de Saúde e a formação dos médicos:
}

um diálogo possível?

CIUFFO, R.S.; RIBEIRO, V.M.B. Brazilian Public Health System and medical training: possible dialog? Interface - Comunic., Saúde, Educ., v.12, n.24, p.125-40, jan./mar. 2008.

This paper discusses the viability of constructing a dialog between medical training and the Brazilian Public Health System (SUS), while emphasizing the principle of integral care as the line structuring this training. The possibilities for such dialog were investigated by analyzing the words of teachers and students in the medical courses at the State University of Rio de Janeiro (UERJ) and the Federal University of Juiz de Fora (UFJF), from focal groups. The results showed that the teachers in these training institutions were aware of the importance of the social commitment that the profession demands, with the changes resulting from this, although some teachers demonstrated resistance towards taking on new challenges. Among the students, discontent with their training prevailed, although there were indications of breaking with the traditional paradigms of medical training and development of projects with health services and the community.

Key words: Medical training. Full care. Curricular innovation. Healthcare skills.
Este artigo discute a viabilidade da construção de um diálogo entre a formação dos médicos e o Sistema Único de Saúde (SUS), enfatizando o princípio de integralidade como eixo estruturante dessa formação. A possibilidade ou não desse diálogo verificou-se na análise das falas de professores e estudantes dos cursos de Medicina da Universidade do Estado do Rio de Janeiro (UERJ) e da Universidade Federal de Juiz de Fora (UFJF) em grupos focais. Os resultados revelam a consciência dos professores das instituições formadoras sobre a importância do compromisso social que a profissão exige, com as decorrentes mudanças, embora alguns demonstrem resistência para enfrentar os novos desafios. Quanto aos estudantes, o descontentamento com a formação é preponderante, embora existam indícios de ruptura com os tradicionais paradigmas da formação médica e desenvolvimento de projetos com os serviços e a comunidade.

Palavras-chave: Formação dos médicos. Integralidade no cuidado. Inovação curricular. Competência em saúde.

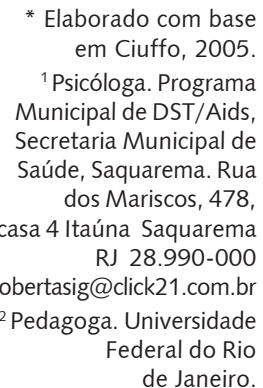

* Elaborado com base 1 Psicóloga. Programa Municipal de DST/Aids, Secretaria Municipal de úde, Saquarema. Rua casa 4 Itaúna Saquarema RJ 28.990-000 de Janeiro. 


\section{Introdução}

Em evidência no cenário das políticas públicas na área de saúde, a formação dos profissionais de saúde (aqui, especificamente, a formação médica) representa terreno árido pelos questionamentos e conflitos que suscita e pelas transformações que requer.

Representando espaços privilegiados de produção de conhecimento e discussão, as escolas ainda refletem e reproduzem a lógica fragmentada própria do cientificismo, deixando de potencializar o que há de mais rico no campo da educação: as relações possíveis de serem desenvolvidas entre professor e estudante que, mais tarde, revertem-se nas relações estabelecidas entre os profissionais e seus pacientes, ou entre quem cuida e quem é cuidado. Retrato, embora parcial, do descaso com a área das relações interpessoais, vem sendo expresso, entre outros resultados, nos baixos índices de resolutividade do Sistema Único de Saúde (SUS), na insatisfação dos usuários e de muitos profissionais dos serviços e na utilização de procedimentos de alto custo, muitas vezes, desnecessários.

Pode-se supor que, como garantido constitucionalmente, o SUS como ordenador de recursos humanos na área de saúde (Art. n. 200) ainda se restrinje à dimensão teórica. Reconhecê-lo como ordenador da formação exige uma profunda reestruturação nos currículos de Medicina, especificamente, a ser realizada por meio de sucessivas e permanentes inovações curriculares, orientadas pelo princípio da integralidade - noção complexa que articula concepções e práticas de saúde - e pela revisão do processo de trabalho e de gestão em saúde. Para isso, fazem-se necessárias as rupturas do paradigma biomédico, que ainda sustenta as práticas em saúde e grande parte dos currículos de Medicina no Brasil; e da concepção simplista de que "ter saúde é não ter doença", o que implica retirar o foco das ações assistencialistas e entender que o cuidado $^{3}$, e não mais a assistência ${ }^{4}$, deve conjugar ações de prevenção de doenças, promoção da saúde, além da cura e da reabilitação - todas exigindo pluralidade de saberes - e o trabalho em equipe interdisciplinar e multiprofissional, preferencialmente em rede.

No entanto, essas ações não se fazem por si só; envolvem uma série de procedimentos e decisões que dependem do poder público, dos gestores dos serviços, da comunidade e, em especial, do aparelho formador. De que maneira, então, os cursos da área de saúde podem se organizar para formar um profissional capaz de trabalhar sob esse novo paradigma?

As Diretrizes Curriculares Nacionais (DCN) para os cursos da área de saúde, homologadas em $2001^{5}$ e resultantes de um processo de discussão entre representantes do governo, professores, estudantes, pró-reitores e diretores de escolas, entre outros, destinam-se a orientar a formação desses profissionais, tendo como base conhecimentos gerais e ênfase no compromisso social. Isso implica repensar o papel da escola que, até então, pouco ou quase nada dialogava com a sociedade.

Se tomadas como um patamar para inovação, essas diretrizes representam, sem dúvida, uma tarefa de vulto para as instituições de ensino superior, pelos novos elementos que introduzem, e que apontam formas de organização e gestão dos processos de ensino até então inéditos na educação de nível superior no Brasil. Propõem-se a orientar os cursos de Medicina, entre outros, para inovar seus currículos de forma que estes se articulem com as necessidades da sociedade brasileira; buscam o "diálogo" dos projetos curriculares com o contexto social do qual a universidade faz parte; objetivam orientar a formação
${ }^{3}$ Neste artigo, adotamos a noção de "cuidado" de Lacerda e Valla (2004, p.95,99): “uma atitude interativa que inclui o envolvimento e o relacionamento entre partes, compreendendo acolhimento, escuta do sujeito, respeito pelo seu sofrimento e pelas suas histórias de vida". Embora a relação entre cuidador e a pessoa que recebe o cuidado seja assimétrica, devem esta presentes a interação, a troca e o respeito pelos diferentes saberes envolvidos.

${ }^{4}$ Em contraposição ao "cuidado em saúde", a "assistência à saúde" pode ser compreendida como o conjunto de intervenções necessárias para se responder a uma queixa, a um sintoma, com base nos dispositivos presentes no sistema de saúde. Não implica, necessariamente, o estabelecimento de vínculos entre o profissional e o usuário do sistema.

5 Em 2001, no Brasil, foram homologadas as Diretrizes Curriculares Nacionais (DCN), para diversos cursos de graduação, iniciando com os da saúde, mais especificamente, Medicina, Enfermagem e Nutrição, definidas na primeira Resolução do CNE/MEC, $\mathrm{n}^{\circ} 04$, de 07/ $11 / 2001$. 
de profissionais que sejam capazes de atuar nos diferentes níveis de atenção à saúde, sendo competentes para trabalhar, sobretudo, na atenção primária e com responsabilidade social. Este é um fato novo que, diferentemente do convencionado, requer alto nível de complexidade técnica.

No entanto, há um longo caminho a percorrer, no qual as universidades exercem papel relevante como um dos agentes desse processo. As escolas médicas encontram-se, em sua maioria, reproduzindo uma formação dicotomizada, expressa na organização curricular disciplinar, fragmentada e focada em especialidades, tendo como campo predominante de prática o hospital universitário, enfatizando práticas em saúde procedimento-centradas e desconsiderando as usuário-centradas.

Neste artigo, são apresentadas e discutidas as concepções de saúde e educação expressas por professores e estudantes dos cursos de Medicina da Universidade do Estado do Rio de Janeiro (UERJ) e da Universidade Federal de Juiz de Fora (UFJF), base sobre a qual acreditamos ser possível analisar a viabilidade do diálogo entre os princípios do SUS e a formação médica.

A pesquisa foi desenvolvida nessas universidades - instituições selecionadas em virtude da expressão de seus cursos de Medicina no cenário educacional por serem públicas e bem-avaliadas pelo sistema nacional de avaliação das IES, embora em estágios diferentes no processo de inovação e com um diferencial de acréscimo: uma delas recebeu auxílio do Programa de incentivos às mudanças curriculares para as escolas médicas - PROMED - e a outra, não. A escolha pretendeu, exclusivamente, observar se existem diferenças significativas nas iniciativas de inovação no currículo médico, ressaltando que, independentemente do auxílio do PROMED, todos os cursos da área de saúde tinham um prazo de três anos para instituir mudanças em seu currículo, de acordo com as DCN, a partir da data de sua homologação.

Os sujeitos da pesquisa são professores e estudantes de Medicina das

${ }^{6}$ Estudantes e professores das duas instituições são identificados pelos códigos: EstUERJ, ProfUERJ, EstUFJF, ProfUFJF. instituições citadas ${ }^{6}$, entrevistados pela técnica do Grupo Focal, que permite a observação da dinâmica interacional entre os participantes, ao mesmo tempo em que "dilui" e descentraliza o papel do pesquisador, na medida em que privilegia as interações, a espontaneidade e a coesão grupal, diferentemente do que acontece em entrevistas individuais.

A análise da concepção de professores e estudantes a respeito da educação dos médicos, por meio da transcrição das falas dos grupos focais, exigiu a apropriação de categorias teóricas e conceitos para orientá-la, dada a complexidade do tema. A construção dessas categorias baseou-se no estudo de autores do campo da educação e da saúde, deixando-se aberta a possibilidade de se construírem outras categorias que complementassem a análise qualitativa no decorrer do processo.

O estudo das inovações curriculares na formação dos profissionais de Medicina e sua relação com o princípio de integralidade do SUS, em tempos de DCN e PROMED, conferem ao termo competência importância fundamental para se compreenderem as inovações que são produzidas nos cursos de Medicina, por ser essa noção eixo estruturante das DCN. Neste estudo, ela é compreendida como a capacidade de os indivíduos mobilizarem suas potencialidades de forma integral, pertinentes a seu campo profissional, em contextos diversos, para resolverem um determinado problema. Isso supõe o desenvolvimento de um conjunto integrado de atributos que os habilitem a conviver em grupo, sensíveis às diferenças interpessoais, com capacidade para avaliar novas situações, enfrentando-as com criatividade. Acredita-se que a incorporação dessa noção nos currículos dos profissionais de Saúde, 
especialmente os de Medicina, representa uma ferramenta para a prática da integralidade no cuidado à saúde.

Quanto à inovação curricular, que consiste em uma categoria em que se confundem e se imbricam também os conceitos de reforma, mudança e transformação, assumimos o significado de melhorias planejadas, duradouras, possíveis de serem medidas, o que leva a crer que a ação de inovar prepara a verdadeira transformação. É um processo que inclui a definição do objeto a se inovar e a construção das estratégias para inovar, sempre em estreita relação com o mundo.

Por fim, a categoria integralidade - cuja amplitude de sentido inclui a concepção ampliada de saúde, a compreensão do Sistema de Saúde, a organização dos serviços, o trabalho em equipe interdisciplinar e a prática da intersetorialidade, além de ser um princípio e uma diretriz constitucionalmente definidos $^{7}$ - completa o quadro teórico de análise.

\section{Sistema Único de Saúde: o que as universidades têm a ver com isso?}

Embora a concepção flexneriana ${ }^{8}$ ainda seja hegemônica na formação médica, tendemos, hoje, à busca da integralidade no cuidado, baseada no conceito ampliado de saúde, tendo como conseqüência reformulações curriculares no ensino e iniciativas de mudanças nas políticas públicas desse campo. Tais iniciativas apontam, de certa forma, um abalo na hegemonia dessa concepção, mesmo não tendo sido convertidas, ainda, em inovações significativas nas práticas em saúde. Afinal, integrar o que há tempo se encontra fragmentado não é tarefa das mais simples.

Podemos entender essa fragmentação como originada nos avanços tecnológicos e científicos e na mercantilização da Medicina que, reforçada pela organização econômica característica do capitalismo, atende mais aos anseios financeiros da indústria farmacêutica e de equipamentos do que às necessidades de saúde da população. Esses avanços produziram efeitos ambíguos: se, por um lado, possibilitaram a cura, o controle e a erradicação de doenças antes consideradas fatais, um melhor prognóstico para pacientes portadores de patologias incapacitantes, a detecção de doenças por exames cada vez mais elaborados e de alto nível de complexidade, resultando no aumento da expectativa de vida da população, por outro, dificultaram a manutenção do "encontro terapêutico" entre o médico e o sujeito que adoece. A incorporação tecnológica, ao deixar de contemplar as subjetividades, diluiu a responsabilidade pela assistência e dificultou o desenvolvimento de uma relação médico/paciente mais socialmente comprometida. Essa relação foi, gradativamente, substituída por prescrições, procedimentos, pedidos de exames e pareceres especializados.

Ressalta-se, aqui, a influência que a economia de mercado exerceu sobre as relações estabelecidas entre sistema de saúde, profissional e usuário. A complexidade dessa influência certamente requer um aprofundamento do tema, o que extrapola os limites deste trabalho. No entanto, cumpre-nos chamar a atenção para o fato de que esse contexto econômico e o desenvolvimento científico e tecnológico se apresentam como fatores determinantes na crise da saúde, conforme observado em algumas declarações, no grupo focal, dos sujeitos sob investigação. A análise dessas determinações e de suas interfaces no campo da saúde merece, por si só, um estudo mais pormenorizado.

Segundo Mendes (1999), para superarmos o paradigma flexneriano,
${ }^{7}$ No texto constitucional, a integralidade está expressa como "atendimento integral".

\author{
${ }^{8}$ As recomendações do \\ relatório de Flexner \\ (1910), que avaliou as \\ escolas médicas \\ americanas por \\ encomenda do governo, \\ influenciam até hoje os \\ currículos de Medicina e \\ têm, entre outras \\ características, a ênfase \\ na formação de \\ especialistas, o que tem \\ significado a exclusão \\ dos fatores sociais, \\ psicológicos, \\ emocionais, entre \\ outros, na compreensão \\ do processo de \\ adoecimento. Neste \\ artigo, também \\ utilizamos a expressão \\ "paradigma \\ flexneriano", conforme \\ Mendes (1999).
}


precisamos construir um novo, que permita dar conta da saúde, vista em sua positividade e como um processo que pode melhorar ou deteriorar conforme a ação de uma sociedade sobre os fatores que Ihe são determinantes. Há, então, de se propor uma mudança de paradigma, o qual esse autor, fundamentado na teoria da produção social, chamou de "produção social da saúde". Decorre daí a idéia de que, para além dos aspectos curativos, as práticas em saúde precisam focalizar os aspectos preventivos e de promoção, uma vez que a saúde é condicionada e determinada por fatores, tais como: alimentação, moradia, renda, transporte, saneamento básico, meio ambiente, educação, lazer e acesso aos bens e serviços essenciais - razão pela qual os níveis de saúde da população expressam o nível de organização econômica e social do país. Isso significa uma profunda transformação na forma de compreender a saúde, não mais entendida com base na unicausalidade do início do século XX, isto é, como ausência de doença. Assumida atualmente como um processo, essa concepção está expressa na Lei $n^{\circ} 8.080 / 90$, que dispõe sobre as condições para que não só se efetivem ações integrais em saúde, como também garantam a organização e o funcionamento dos serviços (Brasil, 1990).

Entretanto, a mudança nessa prática só será possível se incluirmos, na pauta de discussões, a concepção de saúde dos profissionais que atuam no sistema e a instrumentalização teórico-prática necessária para que esses profissionais possam desenvolver ações sanitárias além, é claro, do tratamento e da cura das enfermidades. Estamos nos referindo a uma visão de saúde coletiva em um país "doente", sem investimentos e recursos nesta área, em que não há lugar para excessivo volume de procedimentos custosos e de baixo impacto para a saúde, e a presença de alto contingente de especialistas pressiona os custos com os serviços propedêuticos, tornando problemático o seu controle.

O modelo biomédico, ao enfatizar a formação dos especialistas de forma dicotômica, na qual se separa o "bio" do "psi", ou seja, o biológico da subjetividade, dificulta a compreensão integral do ser humano e de seu processo de adoecimento. Esse modelo, muitas vezes, contribui para a elevação dos custos com a saúde, ao formar profissionais que medicalizam queixas de ordem psicológica e/ou social; e para o agravamento da crise do setor, também vinculada à forma como está estruturada a graduação de Medicina e das outras profissões da área da saúde.

Atualmente, o princípio da integralidade vem se constituindo como eixo norteador da educação em saúde, o que tem provocado inúmeras reflexões a respeito de como formar um profissional médico competente, chamando para o debate universidades, conselhos de saúde e serviços. Incorporado pelo campo educacional, o princípio implica, primeiramente, uma mudança de paradigma na concepção de saúde e, em seguida, a necessidade de integrar, no nível macro, serviços e universidade, no sentido de reorientar os cursos, buscando a relação dos conhecimentos teóricos e científicos com a realidade; e, no sentido micro, o currículo, as disciplinas, os docentes, o conteúdo com práticas pedagógicas dinâmicas que integrem estudantes e os reconheçam como sujeitos ativos de sua aprendizagem. Dessa forma, entendemos que a noção de competência, eixo estruturante das DCN, constitui uma ferramenta para a integralidade no cuidado e elemento-chave para reorientar o projeto e as práticas pedagógicas que sustentam o currículo. Um profissional competente pode ser considerado aquele que integra conhecimento teórico, posturas, valores, atributos, habilidades e consciência clara sobre os contextos social, político, econômico e cultural; sabe conviver em grupo e com diferenças interpessoais; seja capaz de avaliar novas situações e enfrentá-las com criatividade. Portanto, o princípio de integralidade e a noção de competência configuram-se como eixos complementares no que se refere à educação e à saúde.

Com base nas declarações extraídas dos grupos focais, parece evidente, para alguns professores e estudantes, que a universidade possui um importante papel no redirecionamento das práticas vigentes, na medida em que é responsável pelo cuidado à saúde dispensado pelos profissionais que forma. No entanto, o estudo aponta que os métodos pedagógicos, muitas vezes, são incorporados pelos docentes, sem haver uma discussão político-pedagógica (o para quê); ou, em outros casos, há uma extensa discussão a respeito da mudança de paradigma referente ao processo saúde/doença, mas não há clareza de como as práticas pedagógicas podem acompanhar ou responder a esse novo paradigma. A nosso ver, essa é uma questão que deságua diretamente nas discussões sobre estrutura curricular e, mais especificamente, sobre o significado de currículo para docentes e estudantes de Medicina, de modo que se compreenda o direcionamento das reformas curriculares estimuladas, em 
parte, pelas políticas públicas no setor e, em outra, pelo reconhecido baixo impacto das ações em saúde.

A concepção de currículo aqui sustentada apresenta-se como toda ação comunicativa realizada em espaços e ambientes de aprendizagem para formar sujeitos autônomos que se reconhecem como tal e têm a competência necessária e suficiente - tanto do ponto de vista da argumentação quanto do ponto de vista das atitudes e da compreensão do seu papel histórico-social -, para estabelecer relações de entendimento com os sujeitos com os quais convivem, relações essas que se destinam a um acordo consensualmente estabelecido.

Termo polissêmico, currículo não pode ser compreendido desvinculado do contexto social, político, econômico e cultural. Como um projeto pedagógico, encontra-se intimamente ligado às concepções e ideologias de quem o elabora. A forma como este projeto é posto em prática também indica quais interesses e que sociedade pretende formar o grupo que o concebe.

Neste estudo, ao nos referirmos a currículo, vamos além da concepção que o entende como um sistema de ações planejadas para a aquisição de conteúdos, ou como o caminho a ser percorrido pelo aluno para a aquisição de conhecimento tendo, nas disciplinas, a sua fonte e nos métodos didáticopedagógicos, a sua forma. O que está inscrito no currículo não é apenas informação, mas organização do conhecimento que corporifica formas diferentes de agir, sentir, falar e ver o mundo e o eu. Aprender informações no processo de escolarização é, também, aprender uma determinada maneira de agir conhecer, compreender e interpretar a realidade (Popkewitz, 1994).

Nesse sentido, o currículo não está pronto nem dado; não está aprisionado em uma grade préconstruída com disciplinas e respectivas cargas horárias. Idealmente, deve ser continuamente construído e reinventado, com base em práticas pedagógicas sustentadas por crenças e valores compartilhados entre diretores, professores e estudantes, de acordo com a cultura em que estão imersos. Parece-nos claro, portanto, que a formação dos profissionais da saúde e o trabalho no âmbito do SUS devam ser indissociáveis e permanentemente próximos, para que os problemas enfrentados na realidade dos serviços revertam-se em objeto de análise nas aulas dos cursos e contribuam para reconstruir o campo teórico da educação em saúde.

Aproximando-nos das diretrizes do SUS, não fica difícil perceber que o projeto de transformação da assistência à saúde da população brasileira foi concebido sem levar em consideração os atores que fariam o sistema funcionar. Por analogia: uma máquina com tecnologia de ponta e alta complexidade não funciona se não houver alguém capacitado para operá-la. Isso pode ser transcrito para a atual política de Saúde Pública: criou-se um Sistema Único de Saúde, mas os envolvidos em sua implantação, seu funcionamento e sua manutenção não se encontram comprometidos nem preparados para atuar nesse sistema, uma vez que as instituições formadoras não acompanharam, na prática, as mudanças decorrentes dessa nova orientação. Na teoria, é atribuída ao SUS a competência de ordenar a formação de recursos humanos na área de saúde, com base em um novo modelo que integre a formação teórica com a prática nos serviços. Ceccim \& Ferla (2003) trazem os argumentos que nos permitem afirmar a íntima, necessária e urgente relação que a universidade deve estabelecer com o SUS, valendo-se, inclusive, das políticas públicas que vêm sendo implementadas e que garantem esta integração:

O debate sobre a formação e o desenvolvimento na área de saúde como ação estratégica para a condução da agenda de renovação e reforma no setor saúde parte, portanto, do entendimento de que uma profunda reforma setorial, como uma profunda renovação das organizações de saúde, não se faz sem uma política de educação no setor. [...] Apesar de não restar dúvida de que um profundo processo de reformas não pode se fazer sem profundas alterações no perfil ético, técnico e institucional do pessoal que irá atuar [...], nenhuma reforma se fará sem alterar a qualidade das relações de cuidado à saúde, sob pena de aperfeiçoar-se a organização técnica do Sistema e não se gerar, nos usuários das ações e serviços ou na população, a sensação de cuidado [...]. (p.216-7) 


\section{Inovação - um caminho para a transformação?}

Parece haver um certo consenso entre os autores pesquisados sobre a urgência em reformular o currículo dos cursos para a saúde, com vistas a garantir um efetivo cuidado à população que busca atendimento, seja nos postos, clínicas e hospitais, seja no Programa de Saúde da Família (PSF). No entanto, o mesmo, não se pode dizer a respeito do entendimento de inovação curricular: há uma polaridade entre aqueles que acreditam em inovação como mudanças pontuais e superficiais e aqueles que a entendem como parte do processo de transformação.

Almeida (1999) considera inovação como um plano de mudanças que inclui, também, reforma e transformação. Refere-se a alterações isoladas de conteúdos, cargas horárias, criação de novas disciplinas e revisão de processos didáticos, sem que haja qualquer tipo de alteração nas relações sociais entre os sujeitos envolvidos e questionamentos sobre a natureza do contrato da escola. A reforma é compreendida como o processo de constituição dos sujeitos, por meio da construção de espaços coletivos de reflexão, democratização do conhecimento, percepção de que os sujeitos têm possibilidade de ação real. Já transformação está ligada a mudanças na correlação de forças entre os diversos sujeitos e grupos dentro das instituições e entre elas, envolvendo: a) a essência do próprio processo de produção do conhecimento; b) a construção de novos paradigmas referentes aos modelos assistenciais, a intersetorialidade, a articulação estudo/trabalho, o controle social, determinando alterações de conteúdos e processos, e das relações técnicas, sociais e políticas entre os agentes. Dessa forma, fica clara a idéia do autor de que inovação corresponde a uma mudança superficial de formas e conteúdos e a transformação, uma mudança estrutural na maneira de conceber a educação, a saúde e os processos de ensinagem ${ }^{9}$, apontando a necessidade de uma análise crítica dos sujeitos envolvidos sobre a proposta pedagógica institucional.

Já Feuerwerker (2002) compreende que o projeto de transformar a formação médica se faz pela construção do conhecimento, pela força acumulada em pequenas inovações, pela reflexão crítica sobre o cotidiano e sobre as experiências dos envolvidos nesse processo.

No nosso entendimento, à inovação curricular correspondem as alterações que buscam construir novos processos de formação dos profissionais nas suas relações com a estrutura socioeconômica, envolvendo, nessas relações, outras, referentes aos conteúdos, processos e métodos de ensinagem. Inclui, portanto, alterações significativas no currículo, que podem se tornar o embrião de transformações importantes na relação universidade-escola-comunidade.

No campo da educação em saúde, inovar assume também esse sentido. Para tanto, a escola precisa cumprir seu papel para além de atualizar conhecimentos: desenvolver no homem a competência de lidar com o novo e, desse modo, abrir suas lentes para olhar o mundo e ser sujeito das suas transformações.

Articuladas essas visões de inovação àquela que assumimos e ao contexto atual, devemos ainda considerar a profunda mudança no modo de produção, o que tem determinado transformações nas relações sociais, econômicas e, sobretudo, políticas. Um profissional, hoje, precisa desenvolver competência para enfrentar essas relações em um mundo do trabalho globalizado, competitivo e desigual do ponto de vista da distribuição de renda, capital, status social e acesso à educação e à saúde. Logo, espera-se da escola que acompanhe pari passu as transformações constantes do mundo, não somente introduzindo 
inovações no currículo, como também, e sobretudo, mobilizando "corações e mentes" para inserção consciente nesses processos.

Nesse sentido, a viabilidade de se produzirem inovações nos currículos de Medicina está diretamente ligada à concepção de mundo e de homem sustentada pelos atores do âmbito escolar e sua disponibilidade para o exercício da ação-reflexão-ação. Formar profissionais, tendo como eixo norteador as noções de integralidade e competência e a pretensão de inovar, pressupõe que gestores e docentes reconheçam os limites da ciência biomédica e comecem a trabalhar nas interfaces entre o saber médico e outros saberes que se comunicam com a saúde e que, embora desprezados, não são poucos.

Para Feuerwerker (2002), no entanto, as principais tentativas de mudanças curriculares na educação médica brasileira esbarraram, fundamentalmente, em: concepções limitadas do que seria a mudança; inadequações dos cenários de prática aos objetivos pretendidos; baixa capacidade do núcleo coordenador da mudança para romper a lógica formal das disciplinas; falta de capacitação pedagógica do corpo docente e limitações graves de poder.

A palavra de um estudante sinaliza um sintoma e, também, um desejo: as escolas continuam desvinculando teoria de prática, não consideram que a prática sedimenta e dá sentido à teoria, e correm o risco de inviabilizar o desenvolvimento de um profissional competente. Segundo afirma, as tentativas de integração parecem infrutíferas:

Isto é o que estou vendo aqui: a maioria das aulas teóricas é desinteressante, são pouco didáticas, o professor diz que vai passar vídeo, passa um debate de fulano de tal, em que o fulano fala e fala e não chega a lugar algum, todo mundo fica com sono e ninguém vê nada, termina e não sabemos nem o que se estava debatendo. Outra coisa que vejo: temos umas três disciplinas que estão dando a mesma coisa, e elas não se relacionam. Você estuda uma coisa em uma disciplina e, quando vai estudar a outra, você vê que já estudou aquilo mesmo. E prática nessas disciplinas não se vê. (EstUFJF)

A aprendizagem em serviço é uma proposta de tomar os problemas da realidade como objeto da aprendizagem, da docência e da produção de conhecimentos, que se concretizariam como práticas articuladas, inscritas no mundo do trabalho - na "produção de serviços" e no mundo da vida - ou seja, na produção social da saúde (Feuerwerker, 2002).

Percebemos, em muitas falas, o desconhecimento dos professores em relação ao como inovar; uma mistura de angústia e desconforto com impotência. Há o reconhecimento de que o mundo está mudando e de que a universidade precisa refletir essas mudanças em seu projeto pedagógico, a fim de formar um profissional que esteja preparado para enfrentar os desafios impostos pelo mundo da vida, que inclui o mundo do trabalho.

Por outro lado, há também o não saber ao certo como produzir essas mudanças. No campo da educação médica, inovação acarreta mudanças das práticas hegemônicas por outras mais ajustadas às estratégias de Atenção Primária, que supõem: promoção da saúde e intersetorialidade, controle social e superação da dicotomia entre educação e trabalho. Implica também a discussão a respeito do que, de fato, a escola concebe como um profissional competente. São necessárias práticas curriculares que problematizem temas, que democratizem as relações entre professores e estudantes, que reforcem o arsenal do mundo da vida (conhecimentos, valores, experiências), desenvolvendo competências que aumentem o potencial crítico dos atores do processo de ensinagem para que compreendam e atuem criativamente nos mundos do trabalho e social.

Docente e discente, sujeitos da pesquisa, indicam um entendimento de inovação que supera as mudanças pontuais e alcança a mudança de concepção, de idéia, de "pensamento" da escola. Além disso, compreendem que inovação está intimamente ligada ao projeto pedagógico e ao papel da escola em sua relação com a sociedade:

São modificações, mudanças que você possa fazer, tanto na abordagem de como conseguir que esse aluno tenha os conhecimentos, a competência, as atitudes, as posturas, quer dizer, a 


\begin{abstract}
forma como você administra isso em termos de métodos de ensino. Mas também uma mudança comportamental do próprio professor dentro da instituição em relação ao que ele quer e como vai fazer isso, lembrando que o aluno vê o seu professor como o seu modelo. Então, para mim, a inovação vai muito além de simples mudanças pedagógicas ou de simples integração curricular como vocês dizem. (...) Inovação é muito mais do que isso; inovação é uma mudança de concepção educacional da instituição no processo de formação. (ProfUFJF) Acho que, junto com a reforma, tem que estar reformando o pensamento da universidade; isso tem que ser um projeto claro dentro da universidade, que eu não vejo. (EstUERJ)
\end{abstract}

\title{
Competência: uma ferramenta para a integralidade no cuidado à saúde
}

O termo competência vem ocupando espaço na reestruturação de práticas pedagógicas, porém sua compreensão está longe de ser consensual, podendo aí residir tanto sua força quanto sua fragilidade. Força, sim, pois tem suscitado inúmeras discussões, debates e reflexões, o que já indica o potencial intrínseco que o conceito traz no sentido da sua construção coletiva. No entanto, a falta de consenso pode levar à incorporação utilitária de seu significado por parte das instituições educacionais, governamentais e empresariais, e a um conseqüente esvaziamento de seu sentido transformador.

Por sua polissemia, a noção de competência é compreendida de diferentes maneiras pelas diversas correntes e tendências que jogam sobre ela inúmeras interpretações. Sem pretender esgotar este estudo, selecionamos duas correntes que buscam explicar o significado do termo e os determinantes políticos e econômicos que se encontram presentes - de maneira, por vezes, velada - na sua compreensão.

[...] esta polissemia se origina das diferentes visões teóricas que estão ancoradas em matrizes epistemológicas diversas e que expressam interesses, expectativas e aspirações dos diferentes sujeitos coletivos, que possuem propostas e estratégias sociais diferenciadas e buscam a hegemonia de seu projeto político. (Deluiz, 2001, p.23)

Deluiz (2001) reconhece e caracteriza quatro matrizes teórico-metodológicas referentes ao termo competência: a condutivista, a funcionalista, a construtivista e a crítico-emancipatória. Esta última considera a noção de competência como multidimensional, envolvendo aspectos que vão desde o plano individual aos sociocultural, situacional e processual, não podendo ser concebida como mero desempenho; é uma construção balizada por parâmetros socioculturais e históricos.

Em outra dimensão, Markert (2000) afirma que, no termo competência, podemos encontrar um conceito pedagógico universal que reflete o novo patamar dos conceitos de produção, baseado na visão dialética do desenvolvimento das forças produtivas. Nesse sentido, a qualificação depende não só de condições objetivas, mas também de disposições subjetivas - aspectos comportamentais, posturas, valores - que servem de base para a construção da profissionalidade dos trabalhadores, na luta pelo seu reconhecimento e efetivação de seu poder.

O autor direciona a competência técnica (trabalho) e a competência comunicativa para as relações humanas como categorias centrais do conceito integral de competência. Desse modo, ter conhecimento técnico e saber interagir com o grupo de trabalho constituem-se requisitos indispensáveis para um bom desempenho profissional e para garantir autonomia e poder de decisão aos trabalhadores no contexto produtivo, ou seja, na sua experiência concreta de trabalho. Acredita que, com base na aprendizagem orientada pelas/para experiências, se consegue desenvolver competências-chave com o objetivo de superar o processo de dissolução e segmentação sociais, determinado, em muito, pela maneira fragmentada de olhar e pensar o mundo. Essa concepção de aprendizagem, se pensada em termos da formação médica, tem sido uma luta quase inglória daqueles que crêem no processo de ensinagem integrado, de modo a resultar em profissionais capazes de exercerem sua função com fundamento no princípio de integralidade no cuidado, uma vez que iniciativas dessa natureza são pontuais e isoladas, ou, por outro lado, apropriadas pelos docentes de 
forma pouco problematizada ou reflexiva. A fala de um estudante participante do grupo focal tangencia, entre muitos pontos que aborda, esta questão:

\begin{abstract}
A inserção precoce, a forma que encontraram é a Medicina Integral 1, 2 e 3. Precisa ter maior integração entre o básico e o clínico, então criaram o Curso de Extensão, não é disciplina, é curso, é MBA Mecanismos Básicos do Adoecimento. Colocam professores para dar aula e tentar explicar o que eles aprendem na fisiopatologia e os sinais e sintomas. Na verdade, nada se transformou, a essência do currículo, infelizmente, continua a mesma. Como você aprende a MBA? Sentada, sala de aula, professor, só que, ao invés do retroprojetor, tem o datashow. (EstUERJ)
\end{abstract}

Para que se estruture um currículo baseado em competência - o que aponta também para uma aprendizagem orientada para e pela experiência -, importa que os docentes reflitam sobre suas práticas pedagógicas e formas de interlocução com os sujeitos da aprendizagem, estabelecendo uma relação dialógica ${ }^{10}$ com seu público.

A aprendizagem orientada para experiência, seguindo a concepção de Markert, representa, então, uma tentativa de restaurar a capacidade de pensar e compreender integralmente o contexto social, sendo um projeto tanto pedagógico quanto político. Ser competente, conforme se entende neste estudo, não é tão-somente saber sobre algo, mas também ser capaz de atuar sobre este algo, transformá-lo quando necessário, flexibilizá-lo, integrá-lo a outros saberes, outras interlocuções, sempre em busca de um saber e um fazer situados, teoricamente sustentados e socialmente úteis.

Buscando uma inter-relação entre o que está sendo discutido até aqui a respeito do conceito de competência e as atuais políticas públicas resultantes da interface educação e saúde, incluídas aí as DCN, atestamos a preocupação dos órgãos públicos, quer da educação, quer da saúde, de integrar os currículos dos cursos da saúde com os princípios do SUS. Cumpre ressaltar que tal preocupação, negligenciada desde a Constituição de 1988, começa a ter destaque não com a finalidade de se cumprir um preceito legal, mas com vistas a produzir ações eficazes e eficientes sobre a saúde da população (Brasil, 1988).

O terreno para construir essas mudanças vem sendo preparado com programas do Ministério da Saúde, tais como Capacitação e Formação em Saúde da Família (Pólos de Saúde da Família, Cursos de Especialização em Saúde da Família e Residência em Saúde da Família); Profissionalização dos Trabalhadores da Área da Enfermagem (Profae); Qualificação de Equipes Gestoras de Sistemas e Serviços de Saúde (Aperfeiçoamento de Gestores); Desenvolvimento Gerencial de Unidades Básicas de Saúde (Gerus); Especialização em Gestão de Sistemas e Serviços de Saúde (Especialização de Equipes Gestoras); Interiorização do Trabalho em Saúde (Pits); Mestrados Profissionais; Cursos de Formação de Conselheiros de Saúde e do Ministério Público para o controle social; tais programas resultaram em alguns benefícios, entre os quais podem ser citados: a mobilização de pessoas e instituições no sentido de uma aproximação entre os aparelhos formadores e as ações e serviços do SUS; condições de crítica e reflexão sistemática; incentivos aos movimentos por mudanças no processo de formação; mudanças pontuais nos modelos hegemônicos de formação e cuidado em saúde; iniciativa inédita de parceria entre os Ministérios da Saúde (MS) e de Educação (MEC), com o PROMED e o Programa Nacional de Reorientação da Formação Profissional em

\author{
${ }^{10}$ Segundo Araújo \\ (2003), relação dialógica \\ pode ser compreendida \\ como o espaço em que \\ se desenvolverá, em \\ cada um dos elementos \\ envolvidos, o sentido do \\ valor do outro e de sua \\ dignidade. A atitude \\ dialógica na relação \\ professor/estudante se \\ configura como um \\ espaço de conhecimento \\ do eu, do outro e do \\ mundo. A prática do \\ diálogo coloca, frente a \\ frente, professor e \\ estudante num encontro \\ diário, ligados por uma \\ igualdade ontológica, \\ descobrindo-se na \\ mutualidade.
}


Saúde (Pró-Saúde), apoiando financeiramente as escolas que se propunham a mudar seus currículos, de acordo com as DCN e os princípios do SUS (Brasil, 2002).

A política de educação e desenvolvimento para o SUS também aponta caminhos que possibilitam o fortalecimento do diálogo com as instituições formadoras: a implantação dos Pólos de Educação Permanente (Brasil, 2004a), iniciativa que busca maior interlocução entre gestores, serviços, profissionais, usuários, alunos e professores, integrando saúde e educação; o AprenderSUS (Brasil, 2004b), iniciativa cujo objetivo é mobilizar os gestores do SUS, da educação superior e do controle social para pensar e propor compromissos entre os setores da saúde e da educação e construir a atenção integral, dos pontos de vista individual e coletivo. Na verdade, essa iniciativa propôs-se a garantir a adoção da integralidade como eixo das mudanças na formação dos profissionais de saúde, uma mudança significativa do ponto de vista das concepções vigentes. Pensar, então, a formação profissional em saúde com base nos conceitos de competência e integralidade é operar uma profunda transformação na maneira de conceber o sujeito da aprendizagem e o mundo do trabalho.

No texto das DCN, por exemplo, das 22 competências e habilidades listadas para o egresso do curso de Medicina, grande parte indica uma ação, um comportamento, um resultado que 0 profissional deve alcançar, o que, resumidamente, retiramos do texto oficial (Brasil, 2001, p.2-3):

[...] comunicar-se adequadamente com seus colegas de trabalho, pacientes e familiares; realizar com proficiência a anamnese [...]; diagnosticar e tratar corretamente as principais doenças do ser humano [...]; utilizar adequadamente recursos semiológicos e terapêuticos [...]; realizar procedimentos clínicos e cirúrgicos indispensáveis para o atendimento ambulatorial e para o atendimento inicial das urgências e emergências em todas as fases do ciclo biológico $[\ldots]$

Poucas dessas competências referem-se a posturas e valores, como se pode observar naquelas que identificamos, também, no texto das DCN (Brasil, 2001, p.2-3):

[...] lidar criticamente com a dinâmica do mercado e com as políticas de saúde; reconhecer suas limitações e encaminhar, adequadamente, pacientes portadores de problemas que fujam do alcance de sua formação geral; atuar em equipe multiprofissional.

Entretanto, deve-se reconhecer a importância deste documento, pois demonstra claramente a intenção de enfatizar o papel social do egresso e aproximar a formação do médico das necessidades da população, das questões políticas, do trabalho interdisciplinar em prevenção e promoção da saúde. Mesmo que de forma ainda pouco extensa, sua formulação sugere um avanço em termos de inovar o currículo dos profissionais da área.

Por outro lado, grande parte das práticas pedagógicas, que poderiam capacitar os estudantes para um exercício profissional competente, perpetua a fragmentação teoria-prática e muitos docentes ainda acreditam que algumas visitas a Unidades Básicas de Saúde, por si só, quase sempre sem acompanhamento docente, são suficientes para capacitar o profissional, conforme a fala a seguir:

Já fomos ao posto de saúde; eu não tenho a menor estrutura para ficar visitando posto de saúde, mas nós vamos porque faz parte da matéria. Não nos orientaram bem para já irmos lá e acompanharmos as consultas com o paciente. (EstUFJF)

A introdução do termo competência nas diretrizes do currículo médico exige o deslocamento do foco dos processos educativos dos conteúdos disciplinares para os sujeitos que aprendem, gerando a possibilidade de efetiva e contínua aquisição de conhecimento, de forma dialógica, objetivando o reconhecimento recíproco. Nesse sentido, o currículo deve ressaltar as experiências concretas dos sujeitos como situações significativas de aprendizagem.

A necessidade de um novo modus operandi no cuidado à saúde inclui urgência em se processarem transformações na formação dos profissionais da área. Nessa linha, entendemos que o currículo 
orientado por competência pode significar uma possibilidade para instrumentalizar os estudantes de Medicina - e também de outras áreas - para o complexo trabalho que o sistema de saúde exige, sobretudo no nível primário de atenção à saúde, já que, segundo Campos (2003, p.577),

[...] no nível primário, são utilizadas intervenções com enfoque preventivo, comunitário e coletivo, destinadas a atender aos problemas mais comuns da população. Por envolverem determinação múltipla, necessitam de um conhecimento muito diversificado dos profissionais, pois, nesse nível, trabalha-se segundo a lógica da multicausalidade.

Dessa forma, o profissional que atua nesse nível da assistência precisa dispor das competências técnica e comunicativa, precisa ter capacidade de antever os problemas de saúde para que possa desenvolver ações preventivas; necessita de um olhar ampliado para a sociedade, para seus determinantes políticos, econômicos e sociais, de modo a identificar de que maneira esses determinantes se imbricam na forma de sintomas e queixas dos pacientes.

No entanto, foi possível perceber que as escolas médicas estudadas ainda se encontram distantes da elaboração de propostas de currículo orientado por competência, que pressupõe a existência de novas práticas pedagógicas, novos objetivos, novas formas de avaliação e, é claro, a incorporação de um novo paradigma da saúde que não mais a considere como ausência de doença, e sim como um bem-estar psíquico, social e biológico e a associe com qualidade de vida. Observa-se um predomínio de questionamentos, tais como: que médicos queremos formar? Como dar ênfase, efetivamente, à formação generalista, se o conhecimento científico não pára de se especializar? Será que os estudantes querem ser generalistas, já que o profissional mais bem remunerado é o especialista?

Essas são perguntas freqüentes nos grupos focais, não só dos estudantes como também dos professores. Por outro lado, devemos reconhecer que o exercício da dúvida é sempre uma forma saudável de questionar e refletir sobre nossa prática; pois que seja o mote para superarmos os questionamentos teóricos, para termos verdadeiramente ousadia para inovar e coragem - e, por que não, vontade política - para transformar.

\section{Considerações finais}

A reestruturação no campo da saúde não passa apenas por transformações no modelo de ensino médico, uma vez que, sendo compreendida como qualidade de vida, é necessário que pensemos, ao mesmo tempo, em ações multissetoriais relacionadas a aspectos ambientais, habitacionais, nutricionais, geográficos, educacionais, trabalhistas, culturais, de saneamento básico, lazer, entre tantos outros, de modo a garantir a concretização de um projeto que se contraponha ao histórico modelo que excluía a atenção à saúde. A solução passa, indubitavelmente, por uma reformulação mais abrangente nos currículos de outras profissões, mas não é e nem acaba nela.

No entanto, as tentativas de inovação que as escolas médicas investigadas vêm realizando parecem um começo bastante significativo, no sentido de buscar transformações, mesmo que a longo prazo, na ordem de valores, postura e conduta dos agentes que lidam diretamente com a questão da educação e saúde.

O estudo nos aponta que passamos, inegavelmente, por um momento de revisão de práticas e de valores que norteiam não só o exercício profissional como também a própria existência humana. A crise na área da saúde nada mais expressa do que a crise econômica, política e social que o país atravessa. Nesse contexto, repensar o currículo de Medicina, e também de outras profissões, requer repensar o que queremos para a sociedade: se adaptação e/ou conformismo, a escola continuará "produzindo" indivíduos para se adaptarem; mas, se transformação, necessitamos, antes de tudo, rever nosso ser e estar no mundo, nossa disposição para nos transformarmos e, conseqüentemente, para transformarmos as relações que estabelecemos com o outro.

Qualquer transformação, entretanto, é processual, com avanços e recuos, conflitos e resistências. A homologação das DCN e de políticas de incentivo a mudanças na formação médica, por si só, não 
garante uma efetiva transformação nos currículos das faculdades de Medicina e nas relações neles estabelecidas, dada a complexidade que envolve o campo político institucional para uma mudança expressiva no projeto e na prática pedagógica das instituições. Nesse sentido, a universidade não fica imune aos problemas decorrentes das relações de poder, os quais constituem um forte entrave para que se estabeleçam inovações nos currículos, razão pela qual ainda permanecem, em sua maioria, amarrados nas disciplinas e prisioneiros das "grades curriculares". Percebemos esse ponto, embora de forma sutil, em algumas declarações dos sujeitos investigados, o que nos chama a atenção para a urgência da reflexão sobre o sentido e as reais motivações da prática e do exercício docentes.

Por outro lado, o estudo nos mostra o reconhecimento, por parte de professores e estudantes, da realidade social na qual as faculdades estão inevitavelmente imersas, fato este que se identifica em atividades que exigem a promoção do diálogo entre as universidades, os serviços e a comunidade. Constatamos, segundo os sujeitos investigados, que essas atividades vêm sinalizando uma dissonância entre o que lhes mostra a realidade e o currículo vivido na escola médica. Para um conjunto significativo de professores e estudantes, há de se alterar o currículo, de modo a pautá-lo em um novo paradigma da saúde, que seja construído com base nas relações dos estudantes e docentes com a população, com o sistema de saúde, com os programas que estão em implantação para prevenir e promover, de fato, a saúde das comunidades.

Como observamos no depoimento dos professores, há mais suspeitas sobre a necessidade de se processarem alterações em conteúdos, métodos de ensinagem, atividades práticas, do que propriamente ousadia, capacidade estratégica para se conduzirem processos e se ganharem condições políticas para realizá-las, mesmo reconhecendo que o grupo selecionado possui o viés do engajamento nas discussões sobre a reforma do ensino médico - o que representa uma amostra homogênea. Há, também, por parte das escolas, tentativas para inovar seus currículos. No entanto, distintos obstáculos se fazem valer: pouca ou nenhuma capacitação pedagógica por parte dos professores; ausência de suporte teórico referente à área das Ciências Sociais; resistência e falta de arrojo para romper os modelos tradicionais de ensino; receio de introduzir precocemente os estudantes sem uma "boa base" nas ciências básicas e, em contrapartida, a idéia de que inseri-los cedo na prática dos serviços, por si só, já constitui uma inovação, desprezando a necessidade do processo permanente de ação-reflexão-ação; dificuldade para integrar conhecimentos com outras áreas do saber, entre outros.

Ressalta-se ainda o fato de que os docentes-médicos, em especial, desconhecem a linguagem das ciências da educação, pois foram formados por currículos de base tecnicista, que "des-subjetiva" o homem e o isola do cenário cultural do qual faz parte. Decorre, desses aspectos, a dificuldade de se compreender o significado de competência como estratégia que possibilite aos estudantes mobilizarem seus conhecimentos e suas capacidades diante de situações novas, adversas e imprevisíveis, que fazem parte do cotidiano dos serviços de saúde. Os estudantes estão mais esclarecidos sobre essa questão.

De qualquer forma, entre professores e estudantes de ambas as instituições, é unânime que, para se efetuarem inovações significativas no currículo de Medicina, é necessário, primeiramente, que o docente inove sua postura, seu modo de pensar e de conceber a educação e se arrisque a desenvolver novas práticas de ensinagem. Podemos listar outras necessidades para que transformações no currículo de Medicina se efetivem (tendo sempre em mente que a transformação é o resultado de sucessivas e permanentes inovações): 1) refletir criticamente sobre o projeto político que está por trás do perfil do médico a ser formado pela universidade e que concepção de saúde o sustenta; 2 ) inovar na maneira de conceber o mundo e nas práticas pedagógicas que vão concretizar esta concepção; 3) ajustar a formação às necessidades do país, além de discutir o papel do mercado na determinação do perfil do médico; 4) conhecer os fatores que envolvem o processo de ensinagem (teorias da aprendizagem, técnicas e métodos de ensino dinâmicos que desenvolvam profissionais mais "criativos"), uma responsabilidade dos professores; 5) ter vontade política para transformar, sem estagnar-se no plano da idealização, visto que vontade pressupõe uma ação e o que se idealiza nem sempre é viável; 6) reconhecer o ato de educar como um ato político. 
Em vista disso, ao buscarmos uma resposta para a pergunta que titula este estudo, encontramos, entre as instituições pesquisadas, a busca pela construção de um diálogo com o SUS e a certeza da responsabilidade da universidade na reorganização do sistema de saúde. Identificamos, nos depoimentos, especialmente dos docentes, indícios de mudança na concepção de saúde, críticas à postura resistente dos professores e consciência plena da desintegração curricular. No entanto, ficou a suspeita de que esse diálogo, antes de se dar entre a universidade e os serviços, deve acontecer entre os sujeitos integrantes da universidade: diretores, professores, funcionários e estudantes. Mais informalmente, podemos afirmar que o diálogo entre a formação médica e a prática da integralidade deve "começar em casa". Como observamos no estudo, a inserção precoce do estudante, a criação de disciplinas que abordem direta ou indiretamente assuntos referentes à prática nos serviços e/ou à saúde pública, a participação de estudantes na produção científica sobre educação médica articulada à prática nos serviços esvaziam-se caso os sujeitos desse processo não estejam dispostos a reformular - com serenidade e senso crítico - suas posturas, valores e práticas. O diálogo passa a ser possível, sim, pois há um envolvimento nacional nesta direção, mas as distorções, dificuldades e atravessamentos podem ser reforçados pelo modelo econômico existente, bem como pelas lutas de poder, fatores reconhecidos, porém não explorados nesta pesquisa.

De fato, passamos por um momento de efervescência de movimentos, tanto em nível federal quanto estadual e local que, talvez, nunca tenhamos presenciado em relação à efetiva construção do sistema de saúde, com a participação de diversos setores (universidade, serviços, secretarias) e atores (professores, estudantes, comunidade, profissionais, gestores), objetivando formar redes que sustentem um diálogo permanente entre todas as esferas envolvidas nas ações do SUS.

A angústia que ficou presente nas diversas declarações dos docentes, referente ao como inovar, pode levar a pensar que existem fórmulas mágicas, receitas e manuais prontos, o que, certamente (e para infelicidade de muitos), não há. Há, sim, modelos que os estudantes seguem e, muitas vezes, reproduzem - os que não se baseiam exclusivamente no nível de conhecimento acumulado, mas na atitude do docente, na sua postura, nos seus valores. Estes, antes de quaisquer mudanças nos métodos, poderão determinar transformações significativas nos médicos que encontraremos nos consultórios, hospitais, ambulatórios e emergências - desde que desenvolvam competência para lidar com um contexto social, novo e diferente.

Para que se desenvolvam ações em saúde no âmbito do SUS, baseadas nos princípios de integralidade, eqüidade e universalidade, é preciso que o sistema conte com um profissional criativo e que saiba comunicar-se com os usuários e com os demais profissionais do serviço. Profissionais competentes saberão que não é possível padronizar queixas e assumir condutas semelhantes para casos que serão sempre singulares. Caso as práticas em saúde perpetuem a fragmentação do saber e do sujeito, sem dúvida, estaremos fadados ao fracasso. Neste sentido, o desenvolvimento da relação entre professor e aluno que privilegie determinados atributos e posturas, já significaria um grande passo rumo às transformações que tanto almejamos para nos aproximarmos da integralidade no cuidado à saúde. Acrescentam-se a isso iniciativas pedagógicas que estimulem a formação de profissionais com base em práticas interdisciplinares, nas quais estudantes de diversas áreas de saúde desenvolvam atividades teóricas e práticas em conjunto, dialogando, desde sempre, com os outros campos do saber. Dessa forma, a prática da interdisciplinaridade e intersetorialidade, fundamentais para o exercício da integralidade, serão facilitadas.

Para tanto, as orientações das DCN podem garantir que o estudante integre sua subjetividade com sua criatividade, revele sua capacidade de reunir competências técnica e comunicativa para relacionar-se com o outro. Compreender o homem como um ser cuja formação se deve às relações que estabelece durante sua existência eleva os diferentes espaços de ensinagem a um lugar privilegiado, tornando-se um campo rico, onde diversas relações se desenvolvem. Se essas relações forem facilitadas por uma concepção e uma prática de ensino que reconheçam a pluralidade do sujeito da educação (sem tolher sua capacidade de ser diferente) e se houver integração com os serviços e oportunidade de os estudantes entrarem em contato com problemas reais a serem discutidos teoricamente, sem dúvida, serão dados os primeiros passos para o diálogo possível entre a formação médica e o Sistema Único de Saúde. 


\section{Referências}

ALMEIDA, M.J. Educação médica e saúde: possibilidades de mudança. Londrina/Rio de Janeiro: Editora UEL/Abem, 1999.

ARAÚJO, S.M. D. Relação professor-aluno: espaço de edificação do homem. Benjamin Constant, v.9, n.25, p.3-8, 2003. Disponível em: <http://200.156.28.7/Nucleus/media /common/Nossos_Meios_RBC_RevAgo2003_Artigo_1.rtf>. Acesso em: 08 jul. 2004.

BRASIL. Lei Orgânica da Saúde n. 8.080, de 19 de setembro de 1990. Dispõe sobre as condições para a promoção, proteção e recuperação da saúde, a organização e o funcionamento dos serviços correspondentes, e dá outras providências. Brasília, 1990.

Ministério da Educação. CNE/CES. Resolução CNE/CES/MEC n.4. Em 7 de novembro/2001. Institui Diretrizes Curriculares Nacionais do Curso de Graduação em Medicina, Brasília, 2001.

Ministério da Saúde. Portaria n. 198/GM/MS. Em 13 de fevereiro de 2004. Institui a Política Nacional de Educação Permanente em Saúde como estratégia do Sistema Único de Saúde para a formação e o desenvolvimento de trabalhadores para o setor e dá outras providências. Brasília: Ministério da Saúde, 2004a.

Ministério da Saúde. Secretaria de Gestão do Trabalho e da Educação na Saúde. Departamento de Gestão da Educação na Saúde. AprenderSUS: o SUS e os cursos de graduação da área da saúde. Brasília: Ministério da Saúde, 2004b. Disponível em <www.saude.gov.br/sgetes> Acesso em: 03 set. 2004.

Ministério da Saúde. Secretaria de Políticas de Saúde. Coordenação Geral da Política de Recursos Humanos. Programa de incentivos às mudanças curriculares para as escolas médicas - PROMED. Brasília: Ministério da Saúde, 2002.

. Constituição da República Federativa do Brasil. Brasília: 1988.

CAMPOS, C.E.A. O desafio da integralidade segundo as perspectivas da vigilância da saúde e da saúde da família. Ciênc. Saúde Coletiva, v.8, n.2, p.569-84, 2003.

CECCIM, R.B.; FERLA, A.A. Residência integrada em Saúde: uma resposta da formação e desenvolvimento profissional para a montagem do projeto de integralidade da atenção à saúde. In: PINHEIRO, R.; MATTOS, R.A. (Orgs.). Construção da integralidade: cotidianos, saberes e práticas em saúde. Rio de Janeiro: UERJ/IMS/ABRASCO, 2003. p.211-26.

CIUFFO, R.S. Sistema Único de Saúde e a formação dos médicos: um diálogo possível? 2005. Dissertação (Mestrado) - Universidade Federal do Rio de Janeiro, Rio de Janeiro. 2005.

DELUIZ, N. O modelo das competências profissionais no mundo do trabalho e na educação: implicações para o currículo. Bol. Téc. Senac, v.27, n.3, 2001. Disponível em: <http://www.senac.br/informativo/BTS/index.asp>. Acesso em: 25 out. 2007.

FEUERWERKER, L.C.M. Além do discurso de mudança na educação médica: processos e resultados. Rio de Janeiro: Hucitec, 2002.

FLEXNER, A. Medical education in the United States and Canada: a report to the Carnegie Foundation for the advancement of teaching. New York: The Carnegie Foundation, 1910. (Bulletin 4). 
LACERDA, A.; VALLA, V.V. As práticas terapêuticas de cuidado integral à saúde como proposta para aliviar o sofrimento. In: PINHEIRO, R.; MATTOS, R.A. (Orgs.). Cuidado: as fronteiras da integralidade. Rio de Janeiro: Hucitec/Abrasco, 2004. p.91-102.

MARKERT, W.L. Novas competências no mundo do trabalho e suas contribuições para a formação do trabalhador. Trab. Crít., n.2, p.31-43, 2000.

MENDES, E.V. Uma agenda para a saúde. São Paulo: Hucitec, 1999.

POPKEWITZ, T.S. História do currículo, regulação social e poder. In: SILVA, T.T. O sujeito da educação: estudos foucaultianos. Petrópolis: Vozes, 1994. p.173-210.

SILVEIRA, L.M.; BRANT, V.M. Grupo de adesão ao tratamento: espaço de "ensinagem" para profissionais de saúde e pacientes. Interface - Comunic., Saúde, Educ., v.9, n.16, p.91-104, set.2004/fev.2005.

CIUFFO, R.S.; RIBEIRO, V.M.B. El Sistema Único de Salud y la formación de los médicos: ¿ un diálogo posible? Interface - Comunic., Saúde, Educ., v.12, n.24, p.125-40, jan./mar. 2008.

Este artículo discute la viabilidad de la construcción de un diálogo entre la formación de los médicos y el Sistema Único de Salud en Brasil, enfatizando el principio integral como eje estructural de esa formación. La posibilidad o no de tal diálogo se verificó en el análisis de las manifestaciones de profesores y estudiantes de los cursos de medicina de la Universidad del estado de Rio de Janeiro y de la Universidad Federal de Juiz de Fora, estado de Minas Gerais, ambas de Brasil, en grupos focales. Los resultados revelan la consciencia de los profesores de las instituciones formadoras sobre la importancia del compromiso social que la profesión exige, con los cambios resultantes; aunque algunos demuestran resistencia para afrontar los nuevos desafíos. Respecto a los estudiantes, es preponderante el descontento con la formación, pese a la existencia de indicios de ruptura con los paradigmas tradicionales de la formación médica y el desarrollo de proyectos con los servicios la comunidad.

Palabras clave: Educación médica. Cuidado integral a la salud. Innovación curricular. Competencia en salud. 